\title{
PHYSICAL ASSET MANAGEMENT PRACTICES AND QUALITY SERVICE DELIVERY IN LOCAL GOVERNMENTS IN MID NORTH SUB-REGION OF UGANDA
}

\author{
Peter Adoko Obicci ${ }^{1}$ \\ ${ }^{1}$ Uganda Management Institute, Kampala, Uganda
}

\begin{abstract}
Purpose of the study: Amidst soaring use of excellent physical assets, there is less clear understanding of their weight on service delivery. Drawing on the contention that quality services delivery relies on excellent physical assets, the study aimed to establish how physical asset management practices affect quality service delivery in local governments in mid north sub-region of Uganda.

Methodology: The study used cross-sectional design with a quantitative approach. A sample of 131 respondents were targeted and obtained using simple random and purposive sampling of physical asset managers in local governments. Collected data using self-administered questionnaire was analyzed quantitatively (descriptive and inferential statistics) using Statistical Program for Social Scientists (SPSS Ver. 23).

Main Findings: Findings revealed that there was a positive correlation between physical asset management practices (rho.506) and quality service delivery. Accordingly, it was concluded that physical asset management practices, measured in terms of lifecycle planning, risk management, information management and performance management significantly affected quality service delivery in local governments in mid north sub-region of Uganda.
\end{abstract}

Research limitations/implications: The study used quantitative approach in two local governments with probable missed out on qualitative aspects aside difficulty in generalizability. However, it enlightens theoreticians and practitioners in ensuring proper execution of physical asset management practices in engineering, infrastructure, estate, finance and above all public procurement; for the provision of quality services desired and expected by the different stakeholders.

Novelty/Originality of this study: This study parallels those in developed countries which reveal that success in quality service delivery is a result of using excellent physical assets. However, in developing countries studies are nearly nonexistent. Essentially, there is a paucity of research addressing the subject creating a need to study and systematically document elevation of delivery of quality services using excellent physical assets.

Keywords: Physical Asset, Management Practices, Quality Service Delivery, Sub-region, Uganda.

\section{INTRODUCTION}

Quality service delivery has proven to be a topic of importance at the same time contentious in strategic management in all purpose and public procurement in particular propelled by the use of excellent physical assets. Meanwhile, with nearly all governments striving to promote the use of excellent physical assets for the delivery of quality services, more researchers are focusing on exploring the relationship between physical asset management practices and quality service delivery which is still not completely understood especially in developing countries. Against this backdrop, the study aims to fill the gap through generally hypothesizing that different practices of physical asset management individually and collectively affect quality service delivery in local governments. Thus, the study was about physical asset management practices and quality service delivery in local governments in mid north sub-region of Uganda. Physical asset management practices measured in terms of lifecycle planning, risk management. Information management and performance management was the independent variable while quality service delivery featured by responsiveness, reliability, assurance and empathy was the dependent variable.

\subsection{Background to the Study}

World over, governments assign superior weight to the use of excellent physical assets meant to deliver quality services to their citizenry. Failure to strategically manage practices inherent in the elevating excellent physical assets, may lead to poor service delivery. Maletic et al., (2017) opine there are four key practices for proper management of physical assets. According to them, the practices are physical assets lifecycle planning, physical asset risk management, physical assets information management and physical asset performance management.

\footnotetext{
${ }^{1}$ Corresponding Author: adokoadoko@gmail.com
} 
In developed countries, these practices are dearly encouraged to ensure availability of excellent physical assets at the disposal of government organizations for use. However, in developing countries the contrary is true whereby a lesser superior weight is bestowed unto the promotion and use of excellent physical assets as discovered by Hanis et. a., (2011). This has aroused discontents in the beneficiaries of government services. Of recent, policy makers as well as policy have become concerned about the quality of services delivered in their governments.

In Uganda, the quality of service delivered to the citizenry is dwindling by the day. Service delivery in the country is among the poorest delivered in developing world as per documentary evidences in recent studies (Okech, 2016). The studies acknowledge poor quality service delivery in the country. This has greatly affected the realization of the mission of the central as well as the local governments. Despite all the efforts put in place to raise the quality of service delivered to the citizenry, for example, implementation of the recommendations of the annual national local government assessment reports, produced by the Office of the Prime Minister, it's evident that the quality of services delivered to the citizenry remains poor. In the mid north sub-region of the country the situation is even appalling.

Mid north sub-region of Uganda has two higher local governments composed of districts, municipalities, municipal divisional councils, town/urban councils and sub county councils. In total there are 101 local governments in the sub-region created at different period in the history of local governments in the country. However, the local governments can be clustered into two categories. Those local governments which were formed prior to the introduction of Decentralization policy of 1997 and those that came after the policy. The study elected to at least one district to represent each clusters. Gulu district represented the pre-decentralization policy clusters while Agago district the latter. The choice of the two districts was informed by the fact that they had been rated as best performing and worst performing in their clusters according to the annual performance assessment reports from Office of the Prime Minister for the last three years. In the assessment reports, the fundamental issue of concern has been failure by the local governments to properly plan for the use of their available physical assets. The failure exposes management of their physical assets to risks. Additionally, misinformation about the physical assets often mislead the local governments in their performances. All these problems collectively contribute to poor service delivery witnessed presently in the local governments. This has affected not only the quality of services delivered, but also the realization of the mission of the local governments is unlikely attainable.

\subsection{Statement of the Problem}

The Government of Uganda has a goal to achieve all-out quality services to all her citizens by the year 2040. In this regard it has empowered local governments to plan, own and manage their own physical assets that should compel them to deliver quality services to their citizens. There are several strategies (for example, bottom up planning, performance assessment, performance improvement plans, and technical supports to local governments) that contain specific measures to encourage and elevate the use of physical assets in all local governments.

Notwithstanding the said government efforts, there is poor quality services delivered in local governments and even meeting the least expectations and desired of the citizens. The government has officially acknowledged that there is a 'missing link' between resources (physical assets) sunk into producing services and the quality of services delivered, as revealed in annual performance assessment reports by the Office of the Prime Minister. This means there is a gap between service delivery and the practices of managing the physical assets at the disposal of local governments.

Should the 'missing link' gap persist, the all-out services goals may be difficult to achieve? A need for that reason arises to establish why there is a relentless 'missing link' despite government efforts.

\subsection{Objectives of the Study}

The current study attempts to achieve the following objectives:

- To examine the effect of lifecycle planning on quality service delivery

- To examine the effect of risk management on quality service delivery

- To establish the effect of information management on quality service delivery

- To find out the effect of performance management on quality service delivery

\section{LITERATURE REVIEW}

Subheadings:

\subsection{Theoretical Underpinnings}


This study is underpinned by contingency, resource-based and stakeholder theories. These theories were applied to gain an understanding of the theoretical interconnection physical asset management practices of local government to the delivery of quality services to satisfy the needs of local government stakeholders.

In this study, its presumed poor quality service delivery by local governments in mid north region of Uganda is occasioned by failure of the responsible managers to consider contingency factors in the course of executing physical asset management practices. Poor conceptualization of the environmental/contingency factors may lead to poor practices in managing physical assets with likely negative effect on the quality of services delivered to the beneficiaries.

Contingency theory upholds that management should make good use of contingency factors to improve the performance of an organization. In this study, contingency theory was used to explain the institutional variables that manipulate physical asset management practices in addition to the relationship between these practices and performance consequences (Zhang, Linderman \& Schroeder, 2012) of quality service delivery. The use of the theory was therefore necessary to analyze the quality service delivery against the practice of lifecycle planning, risk, information and performance management practices in managing physical assets.

Resource-based theory has been used to examine resources in organizations. It demonstrates why some organizations perform highly whereas others not depending on the use of available resources at their disposal. Resources always permit organizations to achieve superior economic performance. In this study, resource-based theory was used to explain how physical assets obtainable in local government can aid them to accomplish their functions or carry out their activities.

According to the stakeholder theory, the expectations of stakeholders as embroiled in the resource based theory need to be met. Stakeholder theory was developed to help managers and other stakeholders that may possibly be influenced by managerial decisions constructed inside the organization to meet their expectations as well. Those decisions are often about ensuring that the wishes and aspirations of the stakeholders are fulfilled. Stakeholder theory emphases more on quality service delivery than the actual activities of physical asset management practices for quality service delivery. Suffice to note that the theory takes into consideration the interest of all stakeholders while evaluating organization performance since it's a multi-faceted phenomenon. It is useful in addressing stakeholder engagement in the process of physical asset management practices for quality service delivery as in this case of this study.

\subsection{Empirical review}

Quality service delivery is one of the most important topic in strategic management research. It is arguably the most important indicator in measuring the overall success of the organization. An organization's quality service delivery is the measure of standard or prescribed indicators of responsiveness, reliability, assurance and empathy. In short, quality service delivery is meeting the expectations and needs of the beneficiaries using excellent physical assets which aid in the achievement of set targets and objectives (Baum \& Vlok, 2013).

Lifecycle planning of physical assets is a created stage of long-term plans for the effective management of the physical asset from inception to disposal (Yuan et. al. 2017). It has been examined by various scholars and found to affect organizational functioning including service delivery. The results of a study by Hanis et al., (2011) in Indonesia revealed that the overall platforms in the lifecycle management of physical assets have a positive and significant relations in regard to organizational performance. However, a study by Cilia (2014) decried the inadequate models or guidelines to direct practices of managing physical asset common in many organizations which affects service delivery. This agrees with studies that lifecycle planning in physical asset management practices has a positive relationship with organizational functioning and impacts service delivery (Vermiglio, 2011). Therefore, the following hypothesis is proposed;

\section{$H_{1}:$ Lifecycle planning positively affects quality service delivery}

Risk management refers to the comprehension of associated risk as an important factor in ensuring valuable managing of the physical assets in the organization (Thatshayini, Rajini \& Weerasinghe, 2018). Every physical asset has inherent risks and the potential of failures, much as the link between risk and physical asset reliability is not always understandable. However, Mkanadawire (2015) found that proper risk management gives physical asset management a direction and control of organizational functioning especially service delivery. The study then hypothesized that;

\section{$\mathrm{H}_{2}$ : Risk management positively affects quality service delivery.}

Information management involves efficient flows of data across all activities in the course of managing physical assets to realize the mission of an organization. A study by Baum and Vlok (2013) discovered dysfunction information flow and poor decision-making as hindrances in managing physical assets. Similarly, a study conducted by Yuan and Colleagues discovered that a data-driven decision-making process, also eliminated the 
duplicate data collection efforts, which resulted in reducing physical asset inventory expenses in the short term and more effective physical asset management in the long term (Yuan et. al. 2017). Such a reduction in cost could aid in promoting delivery of quality services. This leads to the following hypothesis;

\section{H3: Information management positively affects quality service delivery}

Various scholars studying strategic management have agreed that performance management aids making plans for decision making and focusses on a better future as well. In his study, Ruitenburg (2017) found managers' inadequate knowledge has negative effect on performance management of physical assets in an organization. Hanis et al., (2011) studied the management of physical assets in Indonesia. They found that the management is neither optimal nor the capability of the apparatus adequate in managing physical assets. This is against the backdrop of the fact that the increase in physical asset management practices promote quality service delivery, leading to the hypothesis;

\section{$H_{4}$ : Performance management has a positive effect on quality service delivery.}

\section{METHODOLOGY}

This study proposes a research model based on literature review as well as contingency, resource- based and stakeholder theories. Contingency theory was used to examine the relationship practices in managing physical assets and quality services delivery. Resource-based theory was used to explain the difference a properly managed physical assets could make in satisfying the need and expectations of beneficiaries who ought to be involved in the management process as well. Stakeholder theory was applied to demonstrate how the involvement could be made possible. Based on these, the research model can be seen in Figure 1 below.

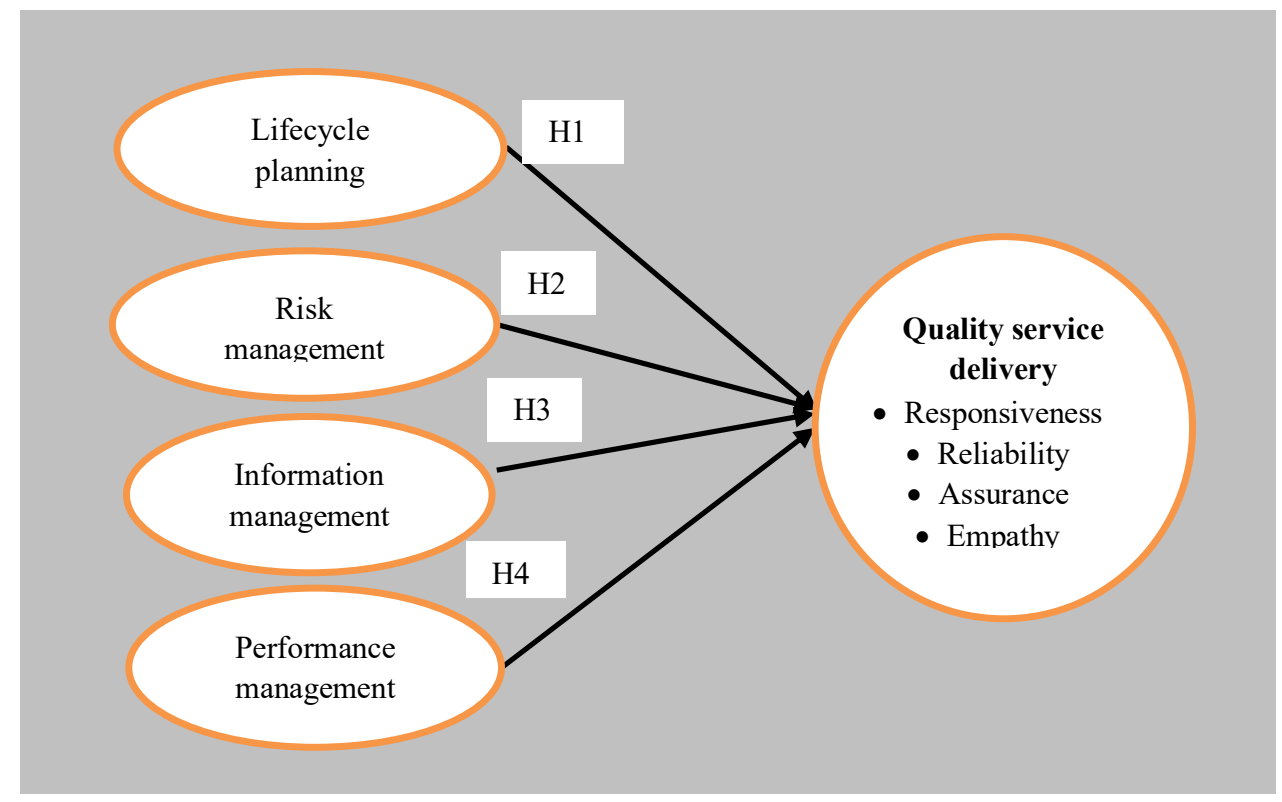

Figure 1: The proposed model

Source: Literature review (Maletǐc et al. 2017).

This study relied on cross-sectional research design as it allows fast collection of data and less expensive. It used quantitative approach for an objective measurement and statistical analysis of collected data from 131 respondents using SPSS computer software. Ethical issues especially of confidentiality, anonymity, voluntariness and informed consent was strictly observed during data collection as well as analysis of the collected data. The assumed knowledge of the respondents on the subject matter, simplicity of questionnaire items and respondents' willingness were all supportive.

\section{RESULTS / ANALYSIS}

\subsection{Response rate and characteristics of respondents}

After examining the returned questionnaire out of 131 distributed, 110 sets were retrieved but only 107 were found useful for further analysis. The response rate was 84 per cent. This a highly acceptable percentage in a research of this nature. Table 1 presents the demographics of those who participated in the study.

Table 1: Summary of demographic data of the respondents 


\begin{tabular}{llll}
\hline Biographic item & Categories & Frequency & Percentage \\
\hline Sex & Male & 60 & 56 \\
& Female & 47 & 44 \\
Age & Total & 107 & 100 \\
& $20-30$ years & 16 & 15 \\
31-41 years & 49 & 46 \\
& $42-52$ years & 29 & 27 \\
Education & 53+ years & 13 & 12 \\
& Total & 107 & 100 \\
& Diploma & 33 & 31 \\
& Bachelor degree & 46 & 43 \\
Tenure & Post Graduate diploma & 17 & 16 \\
& Masters' degree & 11 & 10 \\
& Doctoral degree & 0 & 0 \\
& Total & 107 & 100 \\
& Less than 5 years & 25 & 23 \\
& 5-15 years & 60 & 56 \\
& More than 15 years & 22 & 21 \\
& Total & 107 & 100 \\
\hline
\end{tabular}

Source: Field Survey, 2019/SPSS (Version 23.0 for Windows) Output

Obtained results show that 56 per cent of the involved respondents are male, while the remaining 44 per cent are female. 15 per cent of the respondents are aged between 20 to 30 years, 46 per cent were aged between 31 to 41 years old, 27 per cent were aged between 42 to 52 years old, and 12 per cent were aged $53+$ years old. Through the analysis that has been done, it was found that these respondents possess different educational backgrounds, based on the responses regarding their highest qualification attained. The results show that 31 per cent of them have diploma, 43 per cent have bachelor degree, 17 per cent have post graduate diploma, 11 percent have master's degree and none had a doctoral degree. In terms of tenure of service in local governments 23 per cent had worked for less than 5 years, 56 per cent had worked between 5 to 15 years and 21 per cent of the respondents had worked for more than 15 years.

\subsection{Correlation and regression analysis}

The study used correlation analysis to determine the relationship between the constructs. It also used a multiple regression analysis for determining the quantitative relationship between each of the independent constructs and the dependent construct. The study used a multiple regression model given by $Y=\beta_{1} X_{1}+\beta_{2} X_{2}+\beta_{3} X_{3}+\partial$ to explain the relationship between the constructs. Tables following present the results.

Table 2: Model summary

\begin{tabular}{|c|c|c|c|c|}
\hline Model R & R Square & Adjusted R Square & Std. error of the Estimate & Interpretation \\
\hline $.727^{\mathrm{a}}$ & .5270 & .506 & 2.54054 & Significantly predict \\
\hline
\end{tabular}

a. Predictors: (Constant), lifecycle planning, information, performance, and risk management.

Table 2 gives the model summary of the results. The results indicate that the adjacent $\mathrm{R}$ was 0.506 . This implies that a combination of the practices of lifecycle planning, information, performance, and risk managements accounted for 50.6 of variations in quality service delivery. In spite of this, the model summary cannot fully explain each of the variables. More clarifications of each variables is in ANOVA and coefficient results in the proceeding tables.

Table 3: ANOVA

\begin{tabular}{llllll}
\hline Model & Sum of Squares & Df & Mean Square & F & Sig. \\
\hline Regression & $5.9416 \mathrm{E} 2$ & 94 & $4.4634 \mathrm{E} 2$ & 32.165 & $.008^{\mathrm{b}}$ \\
Residual & $6.110 \mathrm{E} 4$ & 5 & 3254.114 & & \\
Total & $1.253 \mathrm{E} 4$ & & & & \\
\hline
\end{tabular}

a. Dependent construct: Quality service delivery

b. Predictors: (Constant), Lifecycle planning, Risk management, Information management, Performance management 
Source: Field Survey, 2019/SPSS (Version 23.0 for Windows) Output

The above table 3 clarifies that the regression used 94 degrees of freedom and 5 residuals to come up with the multiple $\mathrm{r}$ figures in Table 3. The table also reveals 0.008 significant lower than the required 0.05 .

Table 4: Co-efficient

\begin{tabular}{lllllll}
\hline \multirow{2}{*}{ Model } & \multicolumn{2}{l}{ Unstandardized Co-efficient } & Standardized Co-efficient & \multirow{2}{*}{ t } & \multirow{2}{*}{ Sig. } \\
\cline { 2 - 4 } & B & Std. Error & Beta & & \\
\hline (Constant) & 13.257 & 4.424 & & -.996 & .004 \\
LPP & .332 & .132 & .331 & 1.993 & .044 \\
RMP & .316 & .063 & .411 & 2.508 & .043 \\
IMP & .571 & .147 & .535 & 2.273 & .025 \\
PMP & .557 & .156 & .563 & & \\
\hline
\end{tabular}

a. Dependent Variable: Quality service delivery

Source: Field Survey, 2019/SPSS (Version 23.0 for Windows) Output

From Table 4 above, it can be seen that there is a high effect of information management practice as well as performance management practice on quality service delivery than lifecycle planning and risk management practices which are weaker. Thus based on the regression model above, this translates into $\mathrm{Y}=0.332 \mathrm{X}_{1}$ $+0.0316 \mathrm{X}_{2}+0.571 \mathrm{X}_{3}+0.557 \mathrm{X}_{4}$

\subsection{Hypotheses testing}

Hypotheses of the current study were tested using chi-square as presented in table 5.

Table 12: Chi square Test results

\begin{tabular}{lllll}
\hline $\begin{array}{l}\text { Test } \\
\text { Statistics }\end{array}$ & Lifecycle planning & Risk management & Information management Performance management \\
\hline $\begin{array}{l}\text { Chi- } \\
\text { Square }\end{array}$ & $37.195^{\mathrm{a}}$ & $33.120^{\mathrm{b}}$ & $39.137^{\mathrm{a}}$ & $42.180^{\mathrm{c}}$ \\
Df & 10 & 12 & 11 & 12 \\
Asymp. & .000 & .001 & .000 & .000 \\
Sig. & & & & \\
\hline
\end{tabular}

Source: Field Survey, 2019/SPSS (Version 23.0 for Windows) Output

Results of the four hypotheses disclosed that all the p-values $\left(X^{2}(10)=37.195, p=.000, X^{2}(12)=33.120\right.$, $\left.\mathrm{p}=.000, \mathrm{X}^{2}(11)=39.137, \mathrm{p}=.000, \mathrm{X}^{2}(12)=42.180, \mathrm{p}=.000\right)$ are less than .05 level of significance. Meanwhile, from Table 4, indicates a beta value of each of the variables as lifecycle planning 0.332 , risk management planning 0.316; information management 0.571 and performance management 0.557 . Collectively the sub-constructs predict quality service delivery. This findings is in line with Hanis et al., (2011).

\section{DISCUSSION}

The main aim of the current study was to examine the effect of physical asset management practices on quality service delivery in local governments of Gulu and Agago districts. This discussion section is based on the four objectives stated earlier.

Findings related to objective 1: The first objective of the study examined the effect of lifecycle planning on quality service delivery in local governments of Gulu and Agago districts. Upon the study and testing of objective one, it was found that lifecycle planning has a positive effect on quality service delivery in the selected local governments. The rejected the null hypotheses in preference of the alternate hypothesis $\left(\mathrm{H}_{1}\right)$, that is, $H_{l}$ : Lifecycle planning positively affects quality service delivery. The result is consistent with the studies by Maletic $\mathrm{c}$ et al., (2017) and Hanis et al., (2011).

Findings related to objective 2 with the objective of examining the effect of risk management on quality service delivery was tested by a null hypothesis which was rejected. Given the results indicated risk management has a positive effect on quality service delivery, hence, the alternate hypothesis $\mathrm{H}_{2}$ : Risk management positively affects quality service delivery was accepted. 
The third objective examined the effect of information management on quality service delivery. The objective was studied and a test was conducted on hypothesis $\mathrm{H}_{3}$. Findings did show quality service delivery in the local governments is positively affected by information management. The hull hypothesis used for testing was rejected in place of alternate hypothesis, thus, $H_{3}$ : Information management positively affects quality service delivery was accepted.

Objective 4 sought to find out the effect of performance management on quality service delivery. This objective was studied through hypothesis 4 . The findings of the study and the test of the hypothesis showed a significant and positive effect of performance management on quality service delivery in the local governments. Thus, $\mathrm{H}_{4}$ is accepted in preference to the null hypothesis.

\section{CONCLUSION}

Quality service delivery at inception, design and implementation is critical to realize the mission of any government. Proper practices in managing physical assets at the disposal of any government is the centre-bolt of such an initiative. This study examined the effect of physical asset management practices on quality service delivery in local governments in of Gulu and Agago districts located in mid north region of Uganda. Based on the findings in relation to the four objectives, the study concluded that managers in local governments needed to ensure that lifecycle planning, information, performance and risk management managements be properly executed if local governments are to provide quality services to the beneficiaries.

\section{LIMITATION AND FUTURE RECOMMENDATIONS}

This study used quantitative data at the expense of qualitative ones, a qualitative study is therefore recommended. Again, the study was of a cross-sectional nature which means a longitudinal one is recommendable. This study covered only two local governments and in a single region of Uganda. A similar study could be conducted in more local governments and perhaps regions to generalize the findings other than the local governments of Gulu and Agago districts where the study was conducted.

This study has opened a venture into studying quality service delivery in the ambits of excellent physical assets in local governments. It highlighted the strategic component of lifecycle planning, risk management, information management and performance management which greatly contribute significantly to the delivery of quality services in local governments. Its outputs are very helpful in enhancing the knowledge universe of quality service delivery in the ambits of physical asset management practices. It reaffirmed the importance of contingency, resource-based and stakeholder theories in physical assets. Scholars and researchers are potential beneficiaries of the study in their varied engagement especially for theory validation.

Practically, the study provides local government actors with the tools they required to management their physical assets well as also greatly improve the delivery of quality services in their local governments. Thus, the study could lead to improved quality of services, reduced wastage in physical assets and better use of the potentials of excellent physical assets. In essence, the current study serves as pointer to better enhancement of effective physical asset management practices for quality service delivery in the field of strategic management and public procurement in developing countries and elsewhere.

\section{REFERENCES}

Baum,J., \& Vlok, P.J. (2013). Mapping Primary Constraints in Physical Asset Management Strategy Execution, Using Social Network Analysis. South African Journal of Industrial Engineering, 24(2), 47-58. DOI: 10.7166/24-2-597

Freeman, R. E., \& McVea, J. (2001). A Stakeholder Approach to Strategic Management. Darden Business School Working Paper No. 01-02. DOI.org/10.2139/ssrn.263511

Hanis, M.H., Trigunarsyah, B., \& Susilawati, C. (2011). The application of public asset management in Indonesian local government: A case study in South Sulawesi Province. Journal of Corporate Real Estate. DOI: $\quad 10.1108 / 14630011111120332$

Maletǐc, D., Maletic, M., Al-Najjar, B., Gotzamani, K., Gianni, M., Kalinowski, T. Bartosz. \& Gomiscek, B. (2017).Contingency Factors Influencing Implementation of Physical Asset Management Practices', Organizacija, 50(1), 3-16. DOI: 10.1515/orga-2017-0003

Okech, B.B. (2016). Corruption and Service Delivery in Public Sector of Uganda: Causes and Consequences, Texila International Journal of Management, 2(2), 1-14. DOI: 10.21522/TIJMG.2015.02.02.Art001

Ruitenburg, R.J. (2017). Manoeuvring Physical Assets into the Future - Planning for Predictable and preparing for unpredictable change in Asset Life Cycle Management. PhD thesis, University of Twente,

Enschede, the Netherlands. DOI.org/10.3990/1.9789036543958

Vermiglio, C. (2011). Public property management in Italian municipalities Framework, current issues and viable Solutions. Property Management, 29(5), 423-442. DOI.org/10.1108/02637471111178119 
Yuan, C., Timothy McClure, T., Asce, H.C.M., \& Dunston, P.S. (2017). Life-Cycle Approach to Collecting, Managing, and Sharing Transportation Infrastructure Asset Data. Journal of Construction Engineering Management, 143(6), 1-15. DOI: 10.1061/ (ASCE) CO.1943- 7862.0001288.

Zhang, D., Linderman, K., \& Schroeder, R.G. (2012). The moderating role of contextual factors on quality management practices. Journal of Operations Management, 30, 12-23. DOI.org/10.1016/j.jom.2011.05.001 